Research Journal of Applied Sciences 7 (1): 10-16, 2012

ISSN: $1815-932 \mathrm{X}$

(C) Medwell Journals, 2012

\title{
Development of Shrimp Holder Device for Artificial Insemination of Banana Shrimp Penaeus merguiensis (De Man, 1888)
}

\author{
${ }^{1,3}$ A. J. Memon, ${ }^{1}$ N. Hidayati, ${ }^{1,3}$ A.D. Talpur, ${ }^{1,}$ M.I. Khan, ${ }^{2}$ M.O. Fariddudin, \\ ${ }^{1} \mathrm{~J}$. Safiah, ${ }^{1} \mathrm{M}$. Ikhwanuddin and ${ }^{1}$ A.B. Abol-Munafi \\ ${ }^{1}$ Institute of Tropical Aquaculture, University Malaysia Terengganu, \\ 21030 Kuala Terengganu, Terengganu, Malaysia \\ ${ }^{2}$ Fishries Research Institute, Kg. Pulau Sayak, 08500 Kota Kuala Muda, Kedah, Malaysia \\ ${ }^{3}$ Department of Livestock and Fisheries, Government of Sindh, Sindh, Pakistan
}

\begin{abstract}
In aquaculture industry, spermatophore trans fer technique such as artificial insemination in particular with reference to banana shrimp $P$. merguiensis is challenging. The aim of this study is to examine a novel technique for artificial insemination in P. merguiensis using SHDAI (Shrimp Holder Device for Artificial Insemination). In order to transfer the spermatophore properly into thelycum, an appropriate shrimp holder with continuous aeration system has been developed. During the process of manual spermatophore transfer (artificial insemination) also, a protective device to keep the female $P$. merguiensis shrimps alive and under minimum stress is necessary. The artificial insemination process carried out using SHDAI showed no signs of stress and/or mortality of the broodstock. During the experiments, female shrimps were $100 \%$ alive and active. Altogether, 78 female shrimps were tested of which 63 successfully accepted the spermatophore by using SHDAI. The accepted spermatophore percentage was significantly higher and achieved as $80.76 \%$. Accepted spermatophore mass in the frozen, control and mean of both were recorded as $48.36 \pm 10.45,45.0 \pm 15.28$ and $46.68 \pm 2.38 \%$ which indicated no significant differences $(\mathrm{p}<0.05)$ However, frozen sperm at $-196^{\circ} \mathrm{C} \mathrm{LN}$ up to 90 days was $64.1 \pm 4.3 \%$ which indicated no significant differences between the SHDAI and control $(\mathrm{p}<0.05)$. Whereas frozen sperm at $196^{\circ} \mathrm{C}$ up to 90 days in LN was $62.5 \pm 2.9 \%$ there was no significant difference between the SHDAI and control $(\mathrm{p}<0.05)$. In the present study, overall quality of sperm in terms of the fertilization rate and hatching rate were almost similar between inseminated (using SHDAI) and control (natural mating) broodstock.
\end{abstract}

Key words: Banana shrimp, Penaeus merguiensis, molting, artificial insemination, SHDAI, spermatophore, fertilization, hatching

\section{INTRODUTION}

Artificial Insemination (AI) could improve the ability of fertilization rate and thus certainty of seed production in shrimps (Bart et al., 2006). Artificial insemination is often done to increase the number of offspring of a highquality individual animal and for the breeding of endangered species (McGovern-Hopkins et al., 2003). The technique of AI involves the collection of sperm/ spermatophore from a male and artificially injecting the sperm/spermatophore into a female. AI is usually conducted in situations where the male of the species cannot or should not be involved in the natural mating process properly. AI was the first great biotechnology technique applied to improve reproduction and genetics of animals as reported by Leeuwenhoek. In late 18th century the first successful insemination was performed by Spallanzani and Bonnet (1784) on a dog. Heape (1897) reported that $\mathrm{AI}$ can be used in isolated studies with rabbits, dogs and horses. AI procedure was begun in Russia in 1899 (Ivanoff, 1922). The Japanese scientist Dr. Ishikawa studied similar program in horses in 1912 (Nishikawa, 1962) and this gradually developed into AI application in Japan on cattle, sheep, goats, swine and poultry. In 1936, Brownell inseminated cows in the Cornell herd (Sipher, 1991). AI the most important animal biotechnology applied to date includes improved methods of male management and sperm collection, evaluation, preservation and insemination. This technique is a greatest genetic impact in many species like; swine,

Corresponding Author: A.J. Memon, Institute of Tropical Aquaculture, University Malaysia Terengganu, 21030 Kuala Terengganu, Terengganu, Malaysia 
horses, sheep, goats, dogs, rabbits, poultry and fishes shrimps. The technical aspects of AI are extensively discussed in various studies (Walton, 1933; Anderson, 1945; Cole and Cupps, 1959; Maule, 1962; Mann, 1964; Milovanov, 1964; Perry, 1968; Salisbury et al., 1978; Watson, 1978; Brackett et al., 1981; Foote, 1981; Herman, 1981; Cupps, 1991). Several researches were also carried out on this technique by Nishikawa $(1962,1964,1972)$, Asdell (1969), Bonadonna (1975), Bonadonna and Succi (1976) and Foote (1999).

The majority of shrimp farmers worldwide collect the wild or offspring shrimp from wild-caught broodstock. This practice is risky because wild shrimp may be the carriers of pathogens including viruses. Several of these viruses have been reported to damage the global shrimp farming industry in earlier years (McIntosh, 1999; Moss, 1999). AI has been argued as a way to overcome the lack of mating in closed thelycum shrimp species (Lumare, 1981; Lin and Ting, 1986; Peeters and Diter, 1994). Beside this, comparable spawning performance using naturally mated and artificially inseminated females has been previously reported for P. paulensis (Petersen et al., 1996). Experiments with AI are usually implementing unisex rather than conventional systems ( $\mathrm{Lin}$ and Ting, 1986; Pratoomchaat et al., 1993). Peeters and Diter (1994) reported that artificially inseminated females of $F$. indicus performed equally well either in the presence or absence of males.

The first successful attempt to artificial insemination $P$. paulensis females was performed by Petersen who found similar spawning performance using naturally mated and artificially inseminated females. The efficiency of AI to overcome the lack of mating and improve the reproductive performance compared in conventional versus unisex maturation systems (Peixoto et al., 2004). This study indicated that the presence or absence of males had no effect on the reproductive performance of artificially inseminated females. It might also be possible to optimize the maturation facilities and management by holding females separately from males. The spermatophore could be extruded manually by gently pressing around the coxae of the fifth pair of pereiopods Petersen. The use of one spermatophore to artificially inseminate females proved enough to fertilize three successive spawns with no decrease in hatching rates (Peixoto et al., 2004). In closed thelycum penaeid shrimps, AI must be done soon after molting while the female exoskeleton is still soft and the spermatophore can easily be implanted into the seminal receptacle without causing injuries (Lin and Ting, 1986). Therefore, daily assessment of females is essential to identify those that have recently molted. The majority numbers of shrimp hatchery technician are facing the problem regarding AI especially for $P$. merguiensis and waiting for miracle to be happened.

The major problem in $P$. merguiensis are spermatophore transfer and proper holding the shrimp, spermatophore gets the poor quality in required time which is needed to place it properly in thelycum (Ikhwan, 2010). P. merguiensis are easily stressed by short period in absence of water and indecent gas exchange. For that reason, previous efforts on spermatophore transfer were largely ineffective because of the females were stressed, unable to spawn, released only a few thousand eggs or died. Modification of the currently practiced methods would be important to shrimp seed producers. New development would also make possible use of cryopreserved spermatophore for post-larval production, breeding improvement and management. Upon considering the importance of $\mathrm{AI}$ of $P$. merguiensis, the present study was aimed to bypass this problem. The Shrimp Holding Device for Artificial Insemination (SHDAI) has been developed according to the size of shrimp body which can work as operation tray and allowed gas exchange through water during spermatophore transfer. In this way, it could overcome the stress to the animals.

\section{MATERIALS AND METHODS}

Source of animals: In this study, sexually matured P. merguiensis specimens were collected from Kota Kuala Muda, Palau Sayak, Kedah, Malaysia ( $5^{\circ} 39^{\prime \prime}$ N; $100^{\circ} 19^{\prime \prime}$ E) A total of $(n=39)$ males with mean Body Weight (BW) of $24.2 \pm 3.84 \mathrm{~g}$ and mean Total Length (TL) of $14.4 \pm 0.5 \mathrm{~cm}$ and $(\mathrm{n}=108)$ females with mean BW of $28.1 \pm 6.1 \mathrm{~g}$ and mean TL of $15.4 \pm 0.6 \mathrm{~cm}$ were used throughout the study. They immediately transported to the marine hatchery, at the Institute of Tropical Aquaculture, University Malaysia Terengganu (UMT), in an aerated condition. Precautions were taken to reduce the external stress to the brood stocks by providing ambient environmental conditions during transportation.

Enhance molting: The specimens were maintained in indoor hatchery dark room condition under $26-28^{\circ} \mathrm{C}$. The water salinity provided routine in hatchery was $30 \mathrm{ppt}$. The water salinity manipulated to enhance molting for artificial insemination. The salinity was decreased and increased 2 ppt daily ( $\downarrow \uparrow$ range $30-24$ ppt) until molting. When the shrimp molted thelycum become soft, the spermatophore was inserted into the thelycum. Thus, the sperm was transferred easily into the soft thelycum by using SHDAI. About $6 \mathrm{~h}$ after artificial insemination 
process, the female shrimp was undergone unilateral eyestalk ablation technique by cutting the eyestalk. The shrimp spawned about 1-2 weeks after eyestalk ablation depended on the ovarian stage. The fertilization rate and hatching rate were calculated carefully and data were collected.

General structure of SHDAI (Shrimp Holder Device for Artificial Insemination): The device is constructed from a plastic container (length $=23 \mathrm{~cm}$; width $=13 \mathrm{~cm}$ and height $=7 \mathrm{~cm}$ ) which served as the water reservoir. Aeration hole was at the right side of container from aeration hole, flexible tube was crossed in which air stone fixed for air bubble. A, PVC pipe of $22 \mathrm{~cm}$ long was cut from cross section in two parts. One part was used as an operation tray, along its length $3.5 \mathrm{~cm}$ with the both sides nylon bands were fixed to hold the shrimp. The inside bottom of tube, foam was fixed to prevent shrimp from injuries. Both ends of pipe were fixed in polystyrene sponge. During the spermatophore transfer, female thelycum were exposed between the gape of two nylon bends. A sterile syringe was used to transfer the matured sperm into female thelycum in this way AI was performed (Fig. 1).

Unilateral eyestalk ablation: Eyestalk ablation was performed on females to induce sexual maturation (AQUACOP, 1979). About $6 \mathrm{~h}$ after AI process, the female shrimp were undergone unilateral eyestalk ablation technique by cutting the eyestalk below the eye. It was carried out by securing the female shrimp in a damp towel and pinching of eyestalk was done with red-hot thin forceps that was heated over a Bunsen burner (Primavera, 1985). Unilateral eyestalk ablation was performed on all females within 1 week after the first molting after maturation period (Wyban and Sweeney, 1991).

Artificial insemination by SHDAI and determination the fertilization and hatching capacity: In this study, fresh spermatophore were collected as control A.

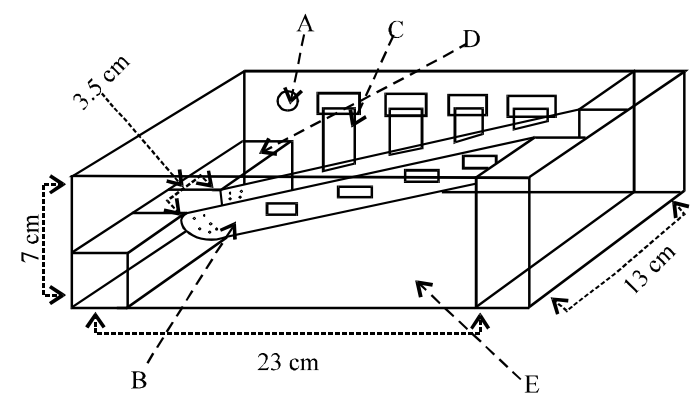

Fig. 1: View of SHDAI (Shrimp Holder Device for Artificial Insemination) ( $\mathrm{A}=$ Aeration hole; $\mathrm{B}=$ PVC pipe $\mathrm{C}=$ Nylon band; $\mathrm{D}=$ Polystyrene sponge; $\mathrm{E}=$ Plastic container)
Spermatophore kept at $2^{\circ} \mathrm{C}$ for $7 \mathrm{~h}$ used as control $\mathrm{B}$. Spermatophore earlier stored in $-196^{\circ} \mathrm{C}$ liquid nitrogen at $6,12,24 \mathrm{~h}, 7,30,60,90,120,150$ and 180 days were used for $\mathrm{AI}$, after the thawing at $27^{\circ} \mathrm{C} / 2 \mathrm{~min}$. About $6 \mathrm{~h}$ after artificial insemination process, the female shrimp was undergone unilateral eyestalk ablation technique by cutting the eyestalk. The shrimp spawned about 1-2 weeks after eyestalk ablation depended on the ovarian stage. The fertilization rate and hatching rate were calculated data were collected.

Statistical analysis: Data ware analyzed as factorial CRD ( 2 factors or more). Analyses of Variance (ANOVA) were analysis using MSTAT C program. The factors involved were CRD; different salinities, time durations and spermatophores frozen groups and control. Means for individually factor were test by LSD $(p>0.05)$ and the interaction were test by Duncan. Parameters means were support by Pearson Correlation (2 tailed).

\section{RESULTS AND DISCUSSION}

Induced molting: For the molting procedure preliminary experiment was done with 30 females. The molting process was enhanced by manipulation of water salinity. The salinity was decreased from 30-24 ppt and increased again from $24-30 \mathrm{ppt}$ for every $2 \mathrm{ppt}$ daily until moulting. There was no shrimp molted at $30 \mathrm{ppt}$ (Table 1). Salinity changes at every 2 ppt triggered moulting in shrimp. The study shows that most $P$. merguiensis female shrimps were

Table 1: Molting performance numbers and percentages in different salinities, periods and treatments of $P$. merguiensis female during preliminary study $(\mathrm{n}=30)$

\begin{tabular}{lcccc}
\hline $\begin{array}{l}\text { Time } \\
\text { (days) }\end{array}$ & $\begin{array}{c}\text { Salinity } \\
\text { (ppt) }+1\end{array}$ & $\begin{array}{c}\text { No. of } \\
\text { shrimps used }\end{array}$ & $\begin{array}{c}\text { No. of shrimps molted } \\
\text { during }\end{array}$ (A-C) treatments & $\begin{array}{c}\text { Shrimps } \\
\text { molted (\%) }\end{array}$ \\
\hline 1 & 30 & 30 & 0 & 0.00 \\
2 & 28 & 30 & 0 & 0.00 \\
3 & 26 & 30 & 0 & 0.00 \\
4 & 24 & 30 & 1 & 3.33 \\
5 & 26 & 29 & 1 & 3.45 \\
6 & 28 & 28 & 4 & 14.29 \\
7 & 30 & 24 & 0 & 0.00 \\
8 & 28 & 24 & 3 & 12.50 \\
9 & 26 & 21 & 2 & 9.52 \\
10 & 24 & 19 & 2 & 10.53 \\
11 & 26 & 17 & 3 & 17.65 \\
12 & 28 & 14 & 7 & 50.00 \\
13 & 30 & 7 & 0 & 0.00 \\
14 & 28 & 7 & 0 & 0.00 \\
15 & 26 & 7 & 0 & 0.00 \\
16 & 24 & 7 & 1 & 14.29 \\
17 & 26 & 6 & 0 & 0.00 \\
18 & 28 & 6 & 0 & 0.00 \\
19 & 30 & 6 & 0 & 0.00 \\
\hline
\end{tabular}

*A-C treatments referred three replications in same salinities and same numbers of shrimps 


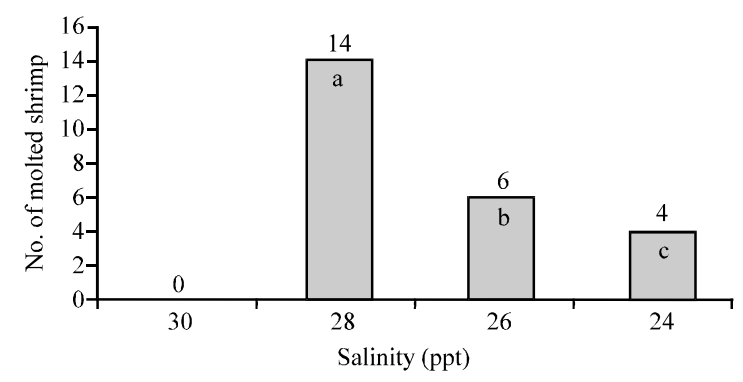

Fig. 2: Total number of females $P$. merguiensis shrimps molted in different salinities and treatments (A-C) in different days (1-19) during the preliminary experiment $(n=30)$. Different letters indicate significant difference among salinities $(\mathrm{p}>0.05)$

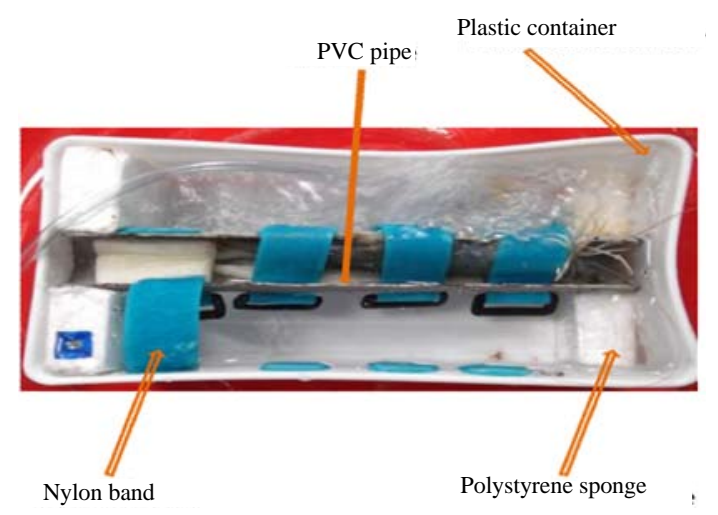

Fig. 3: Novel picture of SHDAI (Shrimp Holder Device for Artificial Insemination)

molted at salinity $28 \mathrm{ppt} 14$ individuals with 6 molted at $26 \mathrm{ppt}$ and 4 molted at $24 \mathrm{ppt}$ (Fig. 2). In this study, it was also observed that there was no significant effect of weight, length observed on molting.

Artificial insemination by SHDAI: The AI process carried out using SHDAI showed no signs of stress in broodstock. It acted like an operation tray, boosting water circulation and aeration over the device. During the experiment, females were kept on device for couple of minutes and released in water tank where it showed normal behavior. Hence, no mortality was observed among the experimental female shrimps (Fig. 3 and 4). In this study showed that out of 78 inseminated females, 63 were successfully accepted the spermatophore by using SHDAI. The accepted spermatophore percentage was significantly higher and achieved as $80.76 \%$ (Fig. 5).

In the above study, the means of accepted spermatophore mass in the frozen, control and mean of both were recorded as $48.36 \pm 10.45,45.0 \pm 15.28$ and $46.68 \pm 2.38 \%$ which indicated no significant differences

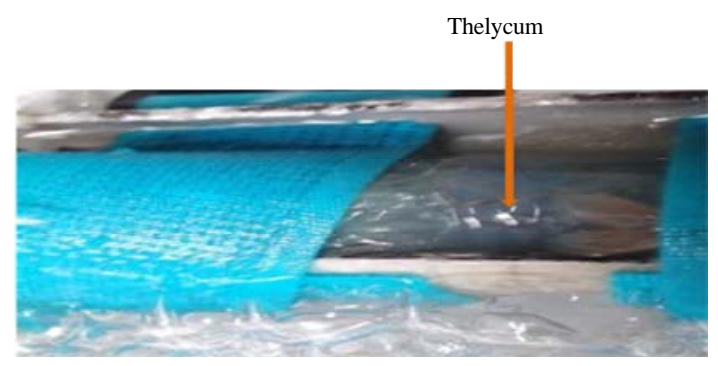

Fig. 4: Exposed thelycum of P. merguiensis before the AI (AKUATROP UMT)

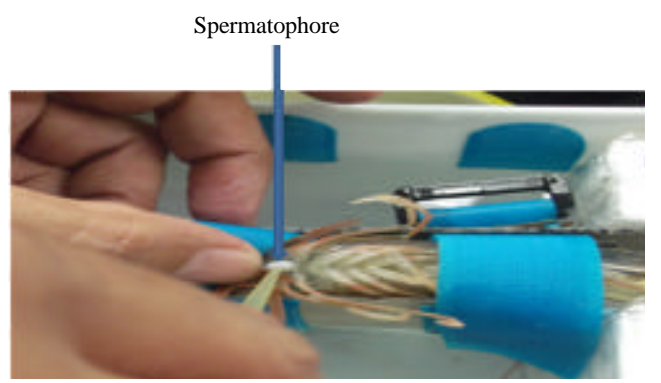

Fig. 5: Transfer of sperm into the thelycum of $P$. merguiensis (AKUATROP UMT)

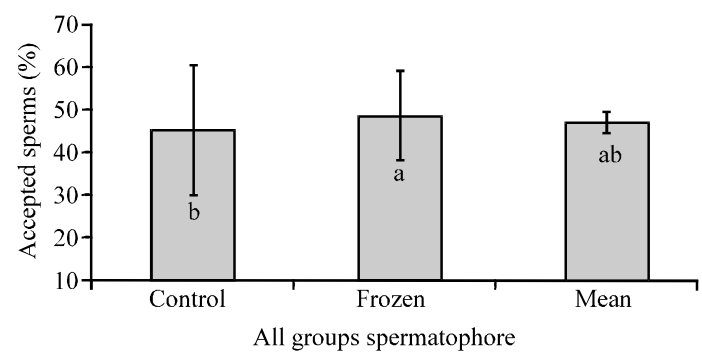

Fig. 6: Females of $P$. merguiensis accepted spermatophore successfully with over all mean by using SHDAI. Different letters indicate significant difference among groups $(\mathrm{p}>0.05)(\mathrm{n}=78)$

$(\mathrm{p}<0.05)$ (Fig. 6). Fertilization was recorded in control A (natural mating and control) $\mathrm{B}$ (Kept spermatophore at $2^{\circ} \mathrm{C}$ for $7 \mathrm{~h}$ ).

The fertilization rate in control A group was $88.2 \pm 5.9 \%$ and control B was $49.7 \pm 6.1 \%$. Whereas, frozen sperm at $-196^{\circ} \mathrm{C} L N$ up to 90 days was $64.1 \pm 4.3 \%$ which indicated no significant differences $(\mathrm{p}<0.05)$ between the SHDAI and control (Fig. 7). Hatching rate in control A was recorded as $76.2 \pm 2.8 \%$ and control B as $64.5 \pm 4.4 \%$. Whereas frozen sperm at $196^{\circ} \mathrm{C}$ up to 90 days in LN was $62.5 \pm 2.9 \%$ and there was no significant difference $(\mathrm{p}<0.05$ ), among the control $\mathrm{A}, \mathrm{B}$ and cryopreserved group (Fig. 8). 


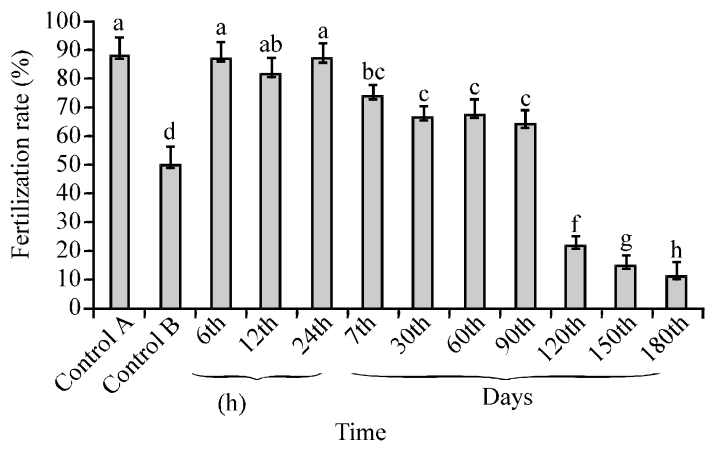

Fig. 7: Fertilization rate over the groups and controls $\left(\mathrm{A}=\right.$ fresh and $\mathrm{B}=$ maintains freshness at $2^{\circ} \mathrm{C}$ up to 7 th $\mathrm{h}$ ). Different letters indicate significant difference among groups $(\mathrm{p}>0.05)(\mathrm{n}=78)$

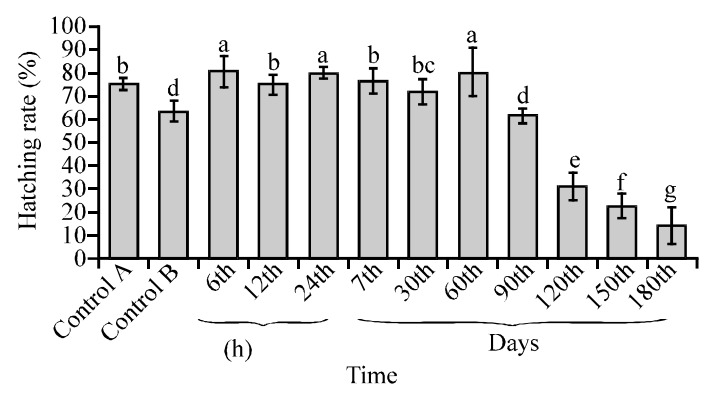

Fig. 8: Hatching rate over the groups and controls $\left(\mathrm{A}=\right.$ fresh and $\mathrm{B}=$ maintained freshness at $2^{\circ} \mathrm{C}$ up to 7 th $\mathrm{h}$ ). Different letters indicate significant difference among groups $(\mathrm{p}>0.05)(\mathrm{n}=78)$

Moulting through manipulation of water salinity: In this study, the manipulation of water salinity was used to enhance molting in female shrimp. There are several factors which have been known to manipulate moulting and growth of shrimp such as food, sex, developmental stage, size and environmental factors (Dall et al., 1990). In the environmental factors, there are certain methods to induce spawning which are temperature, salinity, $\mathrm{pH}$ and light. Those factors can be significantly influence their growth process (Aiken and Waddy, 1980; Boyd, 1990). A study by Vijayan and Diwan (1995) stated that molting and growth in juvenile $P$. indicus were significantly influenced by varying levels of salinity. $P$. indicus exposed to lower (5 ppt) and higher (45 ppt) levels of salinity had lower growth rates and developed muscle necrosis. In present study, the manipulation of water salinity was done by decreased and increased the water salinity at every 2 ppt daily basis (range from 24 ppt until $30 \mathrm{ppt}$ ). Salinities $<5$ and $>35$ ppt usually give negative effect to the shrimp (Lester and Pante, 1992). Vijayan and Diwan (1995), pointed in their study on $P$. indicus produced faster rate with highest growth at salinity of 15 ppt. In this study, $P$. merguiensis shows high percentage of moulting occurs at $28 \mathrm{ppt}$. before the AI molting is a best way for closed thelycum female such as P. merguiensis.

Artificial insemination by SHDAI: The use of SHDAI has facilitated me to achieve much success with manual spermatophore transfer. The use of SHDAI allows for more specific spermatophore transfer and more reduction in stress, unlike the previous methods such as manually spermatophore transfer. In aquaculture industry, spermatophore transfer technique such as artificial insemination, in particular with reference to $P$. merguiensis was challenging and spacious issue. Spermatophore needs to be transfer properly into the thelycum in order to achieve successful insemination. However, this step is a time consuming process and need expert handling for higher success rate. Female shrimps are easily stressed by short periods out of water and early attempts at spermatophore transfer were largely failed. Because the females were stressed and either died as such those were unable to spawn or released only a few thousand eggs so, the quality of eggs was suspected (Tave and Brown, 1981). AI has been claimed as a way to overcome the lack of mating in closed thelycum species (Lumare, 1981; Lin and Ting, 1986; Peeters and Diter, 1994). In this study, artificial insemination process was aided with a new modified device. This device was used to hold the shrimp during transferring the spermatophore into thelycum. Previously, artificial insemination has been done only by using hand to hold the shrimp. So, the shrimp died due to mishandling without water, oxygen and also the more time consume for AI.

Because of new device (SHDAI) there was no sign of stress and nil mortality was recorded during this and whole procedure was done successfully. Earlier study by Tave and Brown (1981) did AI by using device with gill aerator. They stated that $88 \%$ females were spawned successfully which was near to present study as $80.76 \%$. In this study the fertilization rate in control groups $\mathrm{A}$ and B were $88.2 \pm 5.9$ and $49.7 \pm 6.1 \%$ whereas cryopreserved up to 90 days was $64.1 \pm 4.3 \%$ which showed significantly difference among the groups $(\mathrm{p}<0.05)$. The earlier study by Peixoto et al. (2004) stated that the application of artificial insemination techniques as a way to overcome the problems. In his study the percentage of fertilization rate in $F$. paulensis was increased from $26 \%$ before the use of artificial insemination to $57 \%$ afterwards from 125 spawns. The means of hatching rate in this study also recorded the controls $\mathrm{A}$ and $\mathrm{B}$ which were $76.2 \pm 2.8$ and $64.5 \pm 4.4 \%$. Whereas cryopreserved up to 90 days was 
$62.5 \pm 2.9 \%$. However, as reported as Jiang et al. (2009), the hatching rate of the nauplii from artificial insemination was significantly different from control due to quantity and quality of spermatophore inserted. Therefore, successful development of new protocols for improving the artificial insemination of spermatophore becomes a key indicator for the aquaculture potential of this species. Hence, the development of SHDAI for better insemination process would be useful in aquaculture field for $\mathrm{AI}$ of other shrimp species as well.

\section{CONCLUSION}

Enhanced molting by manipulation the water salinity was proved as most efficient at $28 \mathrm{ppt}$ in $P$. merguiensis. An appropriate shrimp holder with continuous aeration system has been developed for better artificial insemination. The AI process carried out using SHDAI showed no signs of stress and/or mortality of the broodstock. During the experiment, female shrimps were $100 \%$ alive and active. Besides, SHDAI as a protective device to keep the female $P$. merguiensis shrimps alive and under minimum stress can be utilized in shrimp aquaculture practices.

\section{ACKNOWLEDGEMENTS}

This research was supported by a grant from the MOSTI (Science Fund) under Project No.: 05-01-12SF1004 and Directorate of Fisheries Inland Hyderabad Government of Sindh, Pakistan. Researchers wish to extend their sincere gratitude to Fisheries Research Institute (FRI), Kg. Pulau Sayak, Prof. Faizah Shaharom, the Ex-Director of AKUARTOP, Universiti Malaysia Terengganu (UMT), Prof. Dr. Anuar Hassan, the Director AKUARTOP UMT for their support throught the study.

Researchers would like to thank all staffs of hatchery/lab of AKUARTOP (UMT) for their constant support and technical assistance throughout this study. Researchers would like to thank Mr. Laiq Ahmed Memon, Secretary Livestock and Fisheries, Government of Sindh, Mr. G.M. Mahar Director General fisheries, Government of Sindh and Mr. G.M. Wadahar Director Fisheries Sindh Inland, Government of Sindh, Pakistan for their extended support for the present study.

\section{REFERENCES}

AQUACOP, 1979. Penaeid reared brood stock: Closing the cycle of $P$. monodon, $P$. stylirostris and $P$. vannamei. Proc. World Maricult Soc., 10: 445-452.
Aiken, D. and S. Waddy, 1980. Reproductive Biology. In: The Biology and Management of the American Lobster, Cobb, S. and B. Phillips (Eds.). Vol. 1, Academic Press, New York, pp: 215-276.

Anderson, J., 1945. The Semen of Animals and its Use for Artificial Insemination. Oliver and Boyd, Edinburgh, Pages: 151.

Asdell, A.A., 1969. Historical Introduction. Academic Press, New York.

Bart, A.N., C. Sudarhma and P.T. Dhirendra, 2006. Spermatophore cryopreservation and artificial insemination of black tiger shrimp, Penaeus monodon (Fabricius). Aquac. Res., 37: 523-528.

Bonadonna, T. and G. Succi, 1976. Artificial insemination of animals in the world. Proceedings of the 8th International Congress on Animal Reproduction and Artificial Insemination, July 12-16, 1976, Krakow, Poland.

Bonadonna, T., 1975. VIth international enquiry into artificial insemination in the world (1971-1973). Zootec. Vet., 30: 2-108.

Boyd, C.E., 1990. Environmental Requirements. Birmingham Publishing Co., Birmingham, UK.

Brackett, B.G., J.G.E. Seidel and S.M. Seidel, 1981. New Technologies in Animal Breeding. Academic Press, New York.

Cole, H.H. and P.T. Cupps, 1959. Reproduction in Domestic Animals. Academic Press, New York.

Cupps, P.T., 1991. Reproduction in Domestic Animals. Academic Press, San Diego, CA., ISBN: 9780121965754, Pages: 670.

Dall, W., B.J. Hill, P.C. Rothlisberg and D.J. Staples, 1990. The Biology of the Penaeid. Academic Press, London, Pages: 489.

Foote, R.H., 1981. The Artificial Insemination Industry Academic Press, New York.

Foote, R.H., 1999. Artificial Insemination from its Origins up to today. Reggio Emilia, Italy.

Heape, W., 1897. The artificial insemination of mammals and subsequent possible fertilization or impregnation of their ova. Proc. R. Soc. London, 61: 52-63.

Herman, H.A., 1981. Improving Cattle by the Millions. University of Missouri Press, Columbia.

Ikhwan, M., 2010. Personal Communication. University Malaysia Terengganu, Malaysia.

Ivanoff, E.I., 1922. On the use of artificial insemination for zootechnical purposes in Russia. J. Agric. Sci., 12: 244-256.

Jiang, S.G., J.H. Huang, F.L. Zhou, X. Chen, Q.B. Yang, W.G. Geng and Z.M. Ma, 2009. Observations of reproductive development and maturation of male Penaeus monodon reared in tidal and earthen ponds. Aquaculture, 292: 121-128. 
Lester, L.J. and M.J.R. Pante, 1992. Penaeid Temperature and Salinity Responses. Elsevier, Amsterdam.

Lin, M. and Y. Ting, 1986. Spermatophore transplantation and artificial fertilization in grass shrimp. Bull. Jpn. Soc. Sci. Fish., 52: 585-589.

Lumare, F., 1981. Artificial reproduction of Penaeus japonicus (Bate) as a basis for the mass production of eggs and larvae. J. World Maricul. Soc., 12: $335-344$.

Mann, T., 1964. The Biochemistry of Semen and of the Male Reproductive Tract. Springer-Verlag, Berlin. Maule, J.P., 1962. The Semen of Animals and Artificial Insemination. Farnham Royal, Commonwealth Agricultural Bureaux, UK.

Maule, J.P., 1962. The Semen of Animals and Artificial Insemination. Farnham Royal, Commonwealth Agricultural Bureaux, UK.

McGovern-Hopkins, K., C.S. Tamaru, G. Takeshita and M. Yamamoto, 2003. Procedural guide for the artificial insemination of the lyretail swordtail, Xiphophorus helleri. Center for Tropical and Subtropical Aquaculture Publication No. 149. http://auscichlids. $\mathrm{com} /$ forum/index.php?action=printpage;topic $=1302.0$.

McIntosh, R.P., 1999. Changing paradigms in shrimp farming: 1. General description. Global Aquacult. Advocate, 2: 40-47.

Milovanov, V.K., 1964. Artificial Insemination of Livestock in the U.S.S.R. Jerusalem: U.S. Department of Commerce, Washington, DC.

Moss, S.M., 1999. Biosecure shrimp production: Emerging technologies for a maturing industry. Global Aquacult. Advocate, 2: 50-52.

Nishikawa, Y., 1962. Fifty Years of Artificial Insemination of Farm Animals in Japan. Kyoto University, Kyoto, Japan.

Nishikawa, Y., 1964. History and development of artificial insemination in the world. Proceeings of the 5th International Congress on Animal Reproduction and Artificial Insemination, September 6-13, 1964, Trento, Italy.

Nishikawa, Y., 1972. Present state of long-term conservation of sperm and its application in various species of domestic animals. Proceedings of the 7 th International Congress on Animal Reproduction and Artificial Insemination, June 6-9, 1972, Munich, Germany.

Peeters, L. and A. Diter, 1994. Effects of impregnation on maturation, spawning and ecdysis of female shrimp Penaeus indicus. J. Exp. Zool., 269: 522-530.
Peixoto, S., R.O. Cavalli, D. Krummenauer, W. Wasielesky and F. D'Incao, 2004. Influence of artificial insemination on the reproductive performance of Farfantepenaeus paulensis in conventional and unisex maturation systems. Aquaculture, 230: 197-204.

Perry, E.J., 1968. The Artificial Insemination of Farm Animals. 4th Edn., NJ Rutgers University Press, New Brunswick.

Pratoomchaat, B., S. Piyatiratitivorakul, P. Menasveta and A.W. Fast, 1993. Sperm quality of pond-reared and wild-caught Penaeus monodon in Thailand. J. World Aquacult. Soc., 24: 530-540.

Primavera, J.H., 1985. A review of maturation and reproduction in closed thelycum penaeids. Proceedings of the 1st International Conference on the Culture of Penaeid Prawns/Shrimps, December 47, 1984, Iloilo City, Philippines, pp: 47-64.

Salisbury, G.W., N.L.Van Demark and J.R. Lodge, 1978. Physiology of Reproduction and Artificial Insemination of Cattle. 2nd Edn., W. H. Freeman Co., San Francisco.

Sipher, E., 1991. The Gene Revolution: The History of Cooperative Artificial Breeding in New York and New England, 1938-1940. Eastern A. I. Cooperative, Inc., Ithaca, NY.

Spallanzani, L. and C. Bonnet, 1784. Dissertations Relative to the Natural History of Animals and Vegetables. J. Murray, London.

Tave, D. and A. Brown Jr., 1981. A new device to help facilitate manual spermatophore transfer in penaeid shrimp. Aquaculture, 25: 299-301.

Vijayan, K.K. and A.D. Diwan, 1995. Influence of temperature, salinity, $\mathrm{pH}$ and light on molting and growth in the Indian white prawn Penaeus indicus (Crustacea: Decapoda: Penaeidae) under laboratory conditions. Asian Fish. Sci., 8: 63-72.

Walton, A., 1933. The Technique of Artificial Insemination. Imperial Bureau of Animal Genetics, Edinburgh.

Watson, P.F., 1978. Artificial breeding of non-domestic animals. Proceedings of the Symposium of the Zoological Society of London, September 7-8, 1977, Academic Press, New York.

Wyban, J.A. and J.N. Sweeney, 1991. Intensive Shrimp Production Technology. Oceanic Institute, Waimanalo, Hawaii, Pages: 158. 